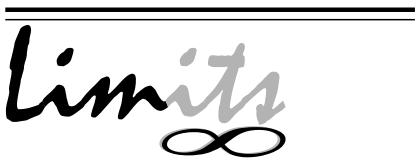

J. Math. and Its Appl.

ISSN : 1829-605X

Vol. 4, No. 1, May 2007, 9-16

\title{
Segitiga Fuzzy-Neural Network untuk Mengenali Pola dari Model Input Data yang Berdistribusi
}

\author{
Hary Budiarto \\ Pusat Teknologi Informasi dan Komunikasi \\ Badan Pengkajian dan Penerapan Teknologi- BPPT \\ hary@iun.bppt.go.id
}

\begin{abstract}
Abstrak
Sistem pengenalan pola seperti pengenalan suara, aroma, wajah, dan tulisan sudah berkembang dengan pesat dan sebagian besar menggunakan metode jaringan syaraf tiruan (JST) seperti multilayer perceptron, back propagation dan lainnya. Pada sistem pengenalan pola secara umum terdapat beberapa komponen yang terintegrasi. Komponen tersebut dikelompokan menjadi 3 bagian yaitu input data, processing data dan output data. Merata-ratakan beberapa nilai yang berdistribusi menjadi sebuah nilai tunggal akan menyebabkan informasi dari nilai-nilai itu akan tereduksi didalam pengenalan pola pada bagian proses pembelajarannya. Dalam paper ini akan dijelaskan suatu metode Segitiga Fuzzy-Neural Network yang dapat memasukan semua informasi dari nilai-nilai yang terukur dari suatu sensor agar lebih merepresentasikan keseluruhan data dan tidak ada informasi yang terreduksi. Hasil pengenalan pola untuk suatu aroma dengan metode ini menunjukan akurasi yang cukup tinggi.
\end{abstract}

Kata Kunci: segitga fuzzy, pengenalan pola, similaritas 


\section{Pendahuluan}

Sistem pengenalan pola seperti pengenalan suara, aroma, wajah, dan tulisan sudah sangat berkembang dan sebagian besar menggunakan metode jaringan syaraf tiruan (JST) seperti multilayer perceptron, back propagation dan lainnya. Implementasi untuk tehnik pengenalan polapun, saat ini banyak sudah dimanfaatkan pada segala bidang antara lain untuk sistem peringatan dini akan bahaya kebocoran gas, quality control untuk aroma, keperluan absensi pegawai dengan sidik jari, authenfication berbagai sistem login, dan lainnya. Pada sistem pengenalan pola secara umum terdapat beberapa komponen yang terintegrasi. Komponen tersebut dikelompokan menjadi 3 bagian yaitu data input, data processing dan data output.

Biasanya pada bagian masukan data dilengkapi dengan alat kontrol yang berfungsi seperti sensor yang akan menerima data dari suatu obyek pengukuran seperti nilai frekuensi, besar temperatur. Untuk perangkat sistem pengenalan pola suatu aroma, pada bagian masukan datanya akan dihubungkan langsung dengan suatu membran sebagai sensornya bila lapisan membran tertempel dengan sesuatu gas atau benda padat mengakibatkan menurunnya nilai frekuensi membran tersebut. Untuk mendapatkan data yang akan diproses pada metode pengenalan pola misalnya sistem Jaringan Syaraf Tiruan (JST) harus dilakukan pengukuran dalam satuan waktu yang dikenal dengan nama snapshot. Data snapshot ini akan diratarata menjadi suatu nilai tunggal yang mewakili satuan waktu, selanjutnya data ini akan diolah pada sistem pengenalan aroma dengan JST untuk melakukan proses pembelajaran yang akan digunakan sebagai model referensi suatu pola tertentu.

Merata-ratakan beberapa nilai yang bedistribusi menjadi sebuah nilai tunggal akan menyebabkan informasi dari nilai-nilai itu akan tereduksi, sehingga hasil untuk pengenalan pola atau model referensinya berakurasi rendah karena tidak semua data terwakili. Paper ini akan menjelaskan suatu metode yang memasukan semua informasi dari nilai-nilai yang terukur dari suatu sensor kedalam bagian input data salah satu jenis metode JST yang dinamakan Fuzzy Neural Network (FNN) agar lebih merepresentasikan keseluruhan data dan tidak ada informasi yang terreduksi. Model input yang berdistribusi ini, akan direpresentasikan dengan menggunakan segitiga fuzzy. Segitiga fuzzy merupakan suatu segitiga samakaki yang mempunyai tinggi sebesar 1 satuan. Bagian alas kaki sebelah kiri segitiga menyatakan nilai minimum dari data yang terdistribusi dan bagian ujung kanannya menyatakan nilai maksimumnya, sedangkan nilai meannya akan berada ditengah-tengah alas segitiga tersebut. Metode FNN dengan menggunakan segitiga fuzzy sebagai input data sudah diimplementasikan pada sistem deteksi aroma, hasilnya menunjukkan bahwa aroma dapat dikenali dengan baik.[1][2] 


\section{Metodelogi Pembelajaran FNN}

\subsection{Segitiga Fuzzy}

Gambar 1 menunjukkan model masukan data yang dinamakan sebagai segitiga fuzzy yang merupakan hasil normalisasi dari 100 data nilai penurunan frekuensi dari pengamatan aroma jeruk Martha Tilaar yang diambil dari sebuah sensor pada suatu waktu pengukuran.[3] Terlihat bahwa karakteristik data hasil pengukuran ditunjukan dengan sebuah segitiga. Apabila data eksperimen bervariasi lebih besar, maka ukuran lebar segitiga fuzzy akan menjadi besar pula.

\begin{tabular}{|l|l|}
\hline Mean & 0,673 \\
\hline Std & 0,003 \\
\hline Max & 0,678 \\
\hline Min & 0,670 \\
\hline
\end{tabular}

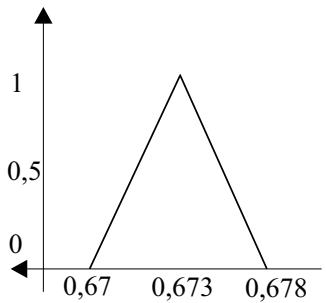

Gambar 1: Model Data dan Segitiga Fuzzy

Selanjutnya nilai tengah dari segitiga fuzzy diatas akan disimbolkan dengan $W_{i j}$ dengan $j$ adalah jenis sensor dan $i$ adalah jenis kategori aroma. Lebar segitiga fuzzy dinyatakan sebagai similaritas atau fuzziness yang mempunyai nilai seperti yang ditunjukkan pada operasi kompetisi dalam Gambar 2 dibawah ini.

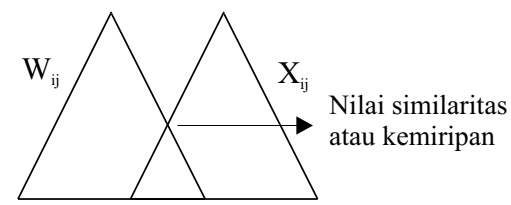

Gambar 2: Operasi kompetisi untuk similaritas

\subsection{Arsitektur Fuzzy Neural Network}

Artsitektur untuk FNN seperti yang ditunjukan pada Gambar3 terdiri dari tiga layer yaitu layer masukan, layer tersembunyi (hidden) dan layer keluaran. Arsitektur ini dicontohkan untuk pengenalan aroma Martha Tilaar yang terdiri dari aroma Mawar, Jeruk dan Kenanga, sehingga layer keluaran terdapat tiga node, sedangkan pada layer masukan mempunyai data dari empat sensor sehingga mempunyai empat node yaitu sensor 1, sensor 2 dan sensor 3. Pengolahan segitiga 


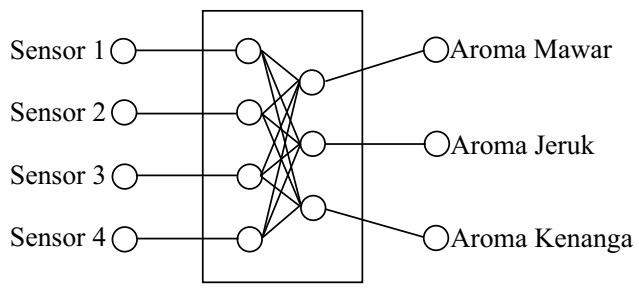

Gambar 3: Arsitektur FNN

Fuzzy terdapat pada layer tersembunyi yang terdiri dari satu lapisan saja yang berisi proses operasi segitiga fuzzy antara data dari lapisan masukan dengan data codebook vector dari lapisan keluaran.

\subsection{Proses Pembelajaran}

Proses pembelajaran merupakan langkah untuk mendapatkan vektor codebook yang berisi segitiga fuzzy referensi untuk seluruh dari setiap kategori aroma yang diinputkan. Proses pembelajaran dari metode FNN mempunyai aturan yang hampir sama dengan metode JST dengan suatu kompetisi yang dinamakan Learning Vector Quantization. Terdapat 3 jenis kasus untuk aturan pada proses pembelajaran dalam melakukan perubahan pada nilai-nilai segitiga fuzzy referensi agar dapat mewakili model pola data.[5] Aturan pertama, bila segitiga fuzzy hasil pengukuran yang dinamakan segitiga fuzzy training mempunyai kategori yang sama dengan segitiga fuzzy referensinya yang memenangkan kompetisi, maka dilakukan pergeseran posisi segitiga referensi dengan mendekati posisi segitiga fuzzy training dan dilakukan pelebaran dispersi (nilai minimum dan maksimum) segitiga tersebut.

Aturan kedua, bila segitiga fuzzy training mempunyai kategori yang berbeda dengan segitiga fuzzy referensi yang memenangkan kompetisi, maka dilakukan pergeseran posisi segitiga referensi dengan menjauhi posisi segitiga fuzzy training dan dilakukan penyempitan dispersi (nila minimum dan maksimum).

Aturan ketiga, bila segitiga fuzzy training dan segitiga fuzzy referensinya tidak ada yang memenangkan kompetisi berarti ditemukan suatu kategori baru, maka semua segitiga referensi akan dilebarkan jangkauan dispersinya (minimum dan maksimum). Pada saat awal pembelajaran, segitiga fuzzy referensi perlu diinialisasikan secara acak. Selanjutnya akhir proses pembelajaran akan mendapatkan segitiga fuzzy referensi berbagai kategori, yang semuanya akan disimpan dalam suatu codebook segitiga fuzzy. 
Tabel 1: Hasil Pengenalan Aroma Martha Tilaar

\begin{tabular}{|c|c|c|}
\hline Input & Output & Similaritas \\
\hline Jeruk & Jeruk & 0.84 \\
\hline Jeruk & Jeruk & 0.85 \\
\hline Jeruk & Jeruk & 0.94 \\
\hline Mawar & Mawar & 0.76 \\
\hline Mawar & Mawar & 0.84 \\
\hline Mawar & Mawar & 0.68 \\
\hline Kenanga & Kenanga & 0.90 \\
\hline Kenanga & Kenanga & 0.88 \\
\hline Kenanga & Kenanga & 0.85 \\
\hline
\end{tabular}

\section{Notasi Matematika Aturan Pergeseran}

Menurut aturan pembelajaran diatas maka untuk kasus pertama yaitu apabila jaringan memberikan hasil yang benar, maka nilai tengah dari segitiga referensi akan diperbarui dengan persamaan sebagai berikut ;

$$
W_{i j}(t+1)=W_{i j}(t)+\alpha(t)\left(\left(1-\mu_{i j}(t)\right)\left(X_{j}(t)-W_{i j}(t)\right)\right)
$$

dengan

$W_{i j}(t+1)$ adalah posisi segitiga fuzzy referensi pemenang setelah digeser

$W_{i j}(t) \quad$ adalah posisi segitiga fuzzy referensi pemenang sebelum digeser

$\alpha(t) \quad$ adalah laju pembelajaran sebesar 0.01

$\mu_{i j}(t) \quad$ adalah nilai similaritas segitiga fuzzy referensi pemenang

$X_{j}(t) \quad$ adalah posisi segitiga fuzzy training

selanjutnya nilai kiri dan kanan segitiga fuzzy referensi pemenang dilebarkan dengan nilai $[0,1]$.

Untuk kasus kedua, yaitu apabila jaringan memberikan hasil yang salah, maka nilai tengah dari segitiga fuzzy referensi akan diperbarui dengan persamaan sebagai berikut;

$$
W_{i j}(t+1)=W_{i j}(t)-\alpha(t)\left(\left(1-\mu_{i j}(t)\right)\left(X_{j}(t)-W_{i j}(t)\right)\right)
$$

selanjutnya nilai kiri dan kanan segitiga fuzzy referensi pemenang disempitkan dengan nilai $[0,1]$.

Untuk kasus ketiga yaitu apabila tidak ada perpotongan antara kedua segitiga fuzzy training dan referensi, maka segitiga fuzzy referensi untuk seluruh kategori dilebarkan dengan menggunakan persamaan sebagai berikut;

$$
W_{i j}(t+1)=W_{i j}(t) k
$$

dengan $k=1,1$ 


\section{Hasil Pengenalan Pola}

Data yang digunakan untuk proses pembelajaran dan pengenalan didapat dari 10 pengukuran atau percobaan yang merupakan perata-rataan dari 100 data persensor per-aroma. Tujuh percobaan secara acak diambil sebagai data untuk pelatihan dan tiga percobaan sisa diambil sebagai data pengenalan. Dalam eksperimen ini digunakan dua kelompok aroma[3], yaitu kelompok aroma Martha Tilaar (jeruk, mawar dan kenanga) dan kelompok aroma ethanol (konsentrasi 0\%, 15\%, $25 \%$ dan $35 \%$ ). Konstanta algoritma pembelajaran yang digunakan adalah konstanta pembelajaran : 0,05 , konstanta pelebaran $\beta: 1,1$ dan penyempitan $\gamma: 0,1$.

Tabel 2: Hasil Pengenalan Aroma Martha Tilaar

\begin{tabular}{|c|c|c|}
\hline Input & Output & Similaritas \\
\hline$C_{1}(0 \%)$ & $C_{1}(0 \%)$ & 0.82 \\
\hline$C_{1}(0 \%)$ & $C_{1}(0 \%)$ & 0.91 \\
\hline$C_{1}(0 \%)$ & $C_{1}(0 \%)$ & 0.86 \\
\hline$C_{2}(15 \%)$ & $C_{1}(0 \%)$ & 0.69 \\
\hline$C_{2}(15 \%)$ & $C_{1}(0 \%)$ & 0.65 \\
\hline$C_{2}(15 \%)$ & $C_{2}(15 \%)$ & 0.80 \\
\cline { 4 - 5 }
\end{tabular}$\quad$\begin{tabular}{|c|c|c|c|}
\hline$C_{3}(25 \%)$ & $C_{3}(25 \%)$ & 0.92 \\
\hline$C_{3}(25 \%)$ & $C_{3}(25 \%)$ & 0.94 \\
\hline$C_{3}(25 \%)$ & $C_{3}(25 \%)$ & 0.80 \\
\hline$C_{4}(35 \%)$ & $C_{4}(35 \%)$ & 0.50 \\
\hline$C_{4}(35 \%)$ & $C_{4}(35 \%)$ & 0.74 \\
\hline$C_{4}(35 \%)$ & $C_{4}(35 \%)$ & 0.57 \\
\hline
\end{tabular}

Dengan menggunakan konstanta-konstanta tersebut diatas, maka kemampuan pengenalan untuk data pelatihan $100 \%$. Sedangkan dengan menggunakan data untuk pengenalan, ternyata kemampuan pengenalan pola mampu untuk mengenali tiga aroma Martha Tilaar adalah $\mathbf{1 0 0 \%}$ benar, dan untuk empat tingkat konsentrasi ethanol kemampuan pengenalan polanya adalah $89.5 \%$. Sebagai perbandingan, algoritma propagasi-balik menggunakan 9 neuron pada lapis tersembunyi juga menghasilkan kemampuan pengenalan yang sama.[3][5] Perbedaannya adalah bahwa algoritma segitiga fuzzy akan lebih cepat mencapai konvergensinya apabila dibandingkan dengan algoritma propagasi-balik. Hasil lengkap dari eksperimen untuk pengenalan pola ini terdapat dalam Tabel 1 dan Tabel 2.

Nilai similaritas yang ditunjukan Tabel 1 dan Tabel 2 pada kolom paling kanan merupakan nilai fuzzines dari segitiga fuzzy referensi ketika memenangkan suatu kategori suatu aroma, hal tersebut dapat diartikan sebagai nilai kemiripan yang dinyatakan dengan nilai dari 0 sampai dengan 1 . Inilah yang menyatakan keunggulan metode FNN untuk suatu input data berdistribusi, pada hasil keluarannya fungsi distribusi datanya masih dapat menghasilkan suatu informasi yaitu nilai kemiripan antara input dan outputnya. Sedangkan untuk pengenalan pola terhadap aroma yang tidak kenal maka salah satu aroma, misalkan jeruk untuk jenis Martha Tilaar dan $C_{4}(35 \%)$ untuk jenis ethanol tidak diikutsertakan dalam pros- 
Tabel 3: Hasil Pengenalan Aroma Unknown (Jeruk) Martha Tilaar

\begin{tabular}{|c|c|c|}
\hline Input & Output & Similaritas \\
\hline Jeruk & Unknown & 0.00 \\
\hline Jeruk & Unknown & 0.00 \\
\hline Jeruk & Unknown & 0.00 \\
\hline Jeruk & Unknown & 0.00 \\
\hline Jeruk & Unknown & 0.00 \\
\hline Jeruk & Unknown & 0.00 \\
\hline
\end{tabular}

\begin{tabular}{|c|c|c|}
\hline Input & Output & Similaritas \\
\hline Mawar & Mawar & 0.50 \\
\hline Mawar & Mawar & 0.58 \\
\hline Mawar & Mawar & 0.59 \\
\hline Kenanga & Kenanga & 0.93 \\
\hline Kenanga & Kenanga & 0.74 \\
\hline Kenanga & Kenanga & 0.59 \\
\hline
\end{tabular}

es pembelajaran. Terlihat pada Tabel 3 bahwa pengenalan terhadap data aroma yang tidak dikenal (jeruk) adalah $100 \%$ benar, begitu pula untuk aroma mawar dan data aroma kenanga.

Percobaan serupa untuk empat tingkat konsentrasi ethanol, hasilnya tertera dalam Tabel 4. Terlihat kemampuan pengenalan terhadap data $C_{1}$ dikenal adalah $90 \%$ benar dan $10 \%$ dikenal sebagai $C_{2}$. Untuk pengenalan aroma $C_{2}$ adalah $90 \%$ benar dan $10 \%$ tidak dikenal. Sedangkan $C_{3}$ dan $C_{4}$ pengenalannya adalah $100 \%$.

Tabel 4: Hasil Pengenalan Unknown Ethanol

\begin{tabular}{|c|c|c|}
\hline Input & Output & Similaritas \\
\hline$C_{1}(0 \%)$ & $C_{1}(0 \%)$ & 0.67 \\
\hline$C_{1}(0 \%)$ & $C_{1}(0 \%)$ & 0.56 \\
\hline$C_{1}(0 \%)$ & $C_{2}(15 \%)$ & 0.58 \\
\hline$C_{2}(15 \%)$ & Unknown & 0.00 \\
\hline$C_{2}(15 \%)$ & $C_{2}(15 \%)$ & 0.54 \\
\hline$C_{2}(15 \%)$ & $C_{2}(15 \%)$ & 0.64 \\
\hline$C_{3}(25 \%)$ & $C_{3}(25 \%)$ & 0.78 \\
\hline$C_{3}(25 \%)$ & $C_{3}(25 \%)$ & 0.54 \\
\hline$C_{3}(25 \%)$ & $C_{3}(25 \%)$ & 0.72 \\
\hline$C_{4}(35 \%)$ & unknown & 0.00 \\
\hline$C_{4}(35 \%)$ & unknown & 0.00 \\
\hline$C_{4}(35 \%)$ & unknown & 0.00 \\
\hline$C_{4}(35 \%)$ & unknown & 0.00 \\
\hline$C_{4}(35 \%)$ & unknown & 0.00 \\
\hline$C_{4}(35 \%)$ & unknown & 0.00 \\
\hline
\end{tabular}




\section{Kesimpulan}

Pengenalan pola dengan model input data terdistribusi telah dikembangkan dan digunakan dalam sistim pengenalan aroma Martha Tilaar dan Ethanol. Terbukti dalam eksperimen bahwa kemampuan pengenalan pola dengan metode FNN terhadap aroma yang dilatihkan sama dengan seperti metode JST dengan algoritma propagasi balik, dengan waktu komputasi yang lebih kecil. Penggunaan algoritma ini telah meningkatkan kemampuan sistim untuk mengenali aroma yang tidak dikenal. Hal ini dilakukan dengan menggolongkan aroma tak dikenal ini kedalam kelompok yang berbeda dengan aroma yang dikenal. Terbukti juga informasi tentang kedistribusian pada hasil akhir pengenalan masih memberikan nilai informasi tentang kemiripannya

\section{Pustaka}

[1] Benyamin Kusumoputro, Hary Budiarto, Wisnu Jatmiko, Fuzzy-neuro LVQ and its comparison with fuzzy algorithm LVQ in artificial odor discrimination system, ISA Transactions Volume 41, Number 4, October 2002

[2] Kusumoputro, Benyamin; Budiarto, Hary; Jatmiko, Wisnu, Fuzzy learning vector quantization neural network and its application for artificial odor recognition system, Proc. SPIE Vol. 4055, p. 374-381, Applications and Science of Computational Intelligence III, Eds.3/2000

[3] B. Kusumoputro and M. Rivai, Discrimination of fragrance odor by arrayed quartz resonator sensor a neural network, ICCIMA-98, H. Selvaraj and B. Verma (Eds), World Scientific, Singapore, 264-270,1998.

[4] L.A. Zadeh, Similarity relations and fuzzy ordering, Information Sciences, $3,177-200,1971$

[5] Y.Sakuraba, T. Nakamoto and T. Moriizumi. New method of learning vector quantization systems and Compt in Japan, 22, 23, 93-102,1991

[6] Zhang, D.Q., Chen, S.C.: Clustering Incomplete Data Using Kernel-based Fuzzy C-Means Algorithm. Neural Processing Letters 18, 155-162, (2003) 